\title{
Technik entscheidet
}

Die richtige Technik war im Sport schon immer wichtig - nur denkt man dabei zunächst weniger an Informationstechnologie (IT), sondern an körperliche Geschicklichkeit. Zunehmend hält aber auch IT im Sport Einzug.

Ein Bereich, bei dem der Einsatz von IT unmittelbar einleuchtet, ist die Organisation großer Sportclubs. Diese sind längst professionell geführte Unternehmen, bei denen IT die gleichen Möglichkeiten zur Produktivitätssteigerung und Rationalisierung bietet, wie in anderen Branchen auch. Das betrifft Bereiche wie Mitgliederverwaltung, Sponsorengewinnung oder etwa die Eigenvermarktung.

Aber auch der Sportler selbst profitiert bereits seit Längerem vom IT-Einsatz und wird das in Zukunft noch umfassender tun. Trainingspläne werden aufgrund von Datenanalysen erstellt und können so passgenau auf einzelne Athleten und deren spezielle Anforderungen abgestimmt werden. Die umfassende Erfassung von Leistungs- und Gesundheitsparametern ist inzwischen Alltag im Profisport. Die Auswertung dieser Daten und der kontinuierliche Abgleich mit der Entwicklung der Leistungsfähigkeit haben das Training auf ein komplett neues Niveau gehoben.

Mit Abstrichen gilt das mittlerweile sogar für den Hobbysport - kaum ein auch nur halbwegs ambitionierter Freizeitsportler verzichtet auf Tracking-Apps, die es ermöglichen, die Entwicklung der eigenen Leistung zu verfolgen. Unter anderem bieten diese meist die Möglichkeit, sich virtuell mit anderen zu messen - für viele eine wichtige Motivation, um dabeizubleiben.

Das alles bedeutet aber keinesfalls, dass menschliche Trainer mittelfristig überflüssig werden. Die Technik ist ein Hilfsmittel für die Fachleute, kann und soll diese aber nicht ersetzen. Wie im von Garry Kasparov entwickelten Advanced Chess, sind Mensch und Maschine zusammen besser als jeweils allein.

Es grüßt Sie herzlich

Peter Pagel

Chefredakteur

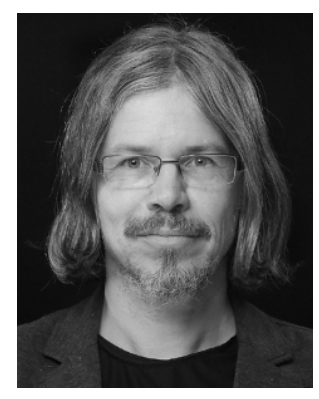

Peter Pagel $(\bowtie)$

peter.pagel@springer.com

Wiesbaden, Deutschland
Wirtschaftsinformatik \& Management 2020 • 12 (5): 305 https://doi.org/10.1365/s35764-020-00293-9

(c) Springer Fachmedien Wiesbaden GmbH, ein Teil von Springer Nature 2020 